\title{
Effect of Chickpea and Okara Composite Flours on The Quality of Instant Noodles
}

\author{
Ng Hui Kuen, Mansoor Abdul Hamid, Hasmadi \\ Mamat, Jahurul Haque Akanda \\ Faculty of Food Science and Nutrition \\ Universiti Malaysia Sabah \\ Sabah, Malaysia \\ mah_chotey@yahoo.com.my
}

\author{
Fisal Ahmad \\ Department of Food Science \\ Universiti Malaysia Terengganu \\ Universitas Brawijaya \\ Terengganu, Malaysia
}

\begin{abstract}
The study has utilized chickpea and okara composite flours and produced best formulation based on sensory and physicochemical characteristics. Formulation of F3 which comprised of $75 \%$ of wheat flour, $12.5 \%$ of chickpea flour and $12.5 \%$ of okara flour was selected as the best formulation. The qualities of best formulation and control were compared through proximate analysis, dietary fiber, energy content and cooking qualities. F3 was better than control in terms of significantly higher ash, crude protein, crude fiber contents and significantly lower crude fat, carbohydrates and energy contents, and it also rich in dietary fiber $(10.05 \mathrm{~g} / 100 \mathrm{~g})$. Furthermore, F3 has significantly higher cooking yield, longer optimal cooking time, lower rehydration rate and higher cooking loss. The storage quality of the best formulation's accelerated shelf life study for eight months was evaluated via water activity test, physicochemical tests, microbiological and sensory tests. The increased in water activity and decreased in $\mathrm{pH}$ value, reduced brightness, increased redness and yellowness of noodles, reduced tensile strength and changes in the textural properties. Nonetheless, the noodles were still safe to be consumed and accepted by the panellists. To conclude, the incorporation of chickpea and okara flours into the instant noodles boosts the nutrient contents but results in poorer textural properties. Further study regarding the alternatives to improve the textural properties of the noodles would be worthwhile.
\end{abstract}

Keyword- instant noodles; chickpea; okara,; nutritional values; physicochemicalproperties; cooking quality

\section{INTRODUCTION}

Noodles are one of the staple foods consumed mainly in Asian countries (EUROMONITOR, 2015). The noodles are made up of dough consisting flour particularly wheat flour, water, common salt, or a mixture of alkaline salts with other raw materials like eggs, additives, and spices. There are numerous factors contribute to the popularity of the instant noodles worldwide which are taste, convenience, long shelf life as well as the reasonable prices. The consumption of instant noodles in more than 80 countries and are internationally recognized food. The consumption of the instant noodles experienced a drastic increase worldwide recently. The sales of instant noodles was 109,390,00 tonnes in 2015 from 105,140,00 tonnes in 2014 (Euromonitor, 2015). In addition, according to World Instant Noodle Association (WINA) (2015), Malaysia ranked $13^{\text {th }}$ place in the global demand for the instant noodles. Furthermore, the forecast sales of instant noodles are estimated to be $113,590,00$ tonnes in the year of 2016 and up to $129,650,00$ tonnes in 2020 (Euromonitor, 2015).

The current instant noodles in the market are primarily comprised of wheat flour which has moderately low nutritional values. Based on a survey by Bread Research Institute of Australia, fried instant noodles consists of $21.1 \%$ of fat, $9.5 \%$ of protein, $6.6 \%$ of moisture, and $1.7 \%$ of ash. The instant noodles available contain insufficient dietary fibre due to the wheat flour as the major ingredient which is low in fibre (Onyema et al., 2014). Moreover, the incomplete protein profile in instant noodle is one of the problems arose as the wheat flour one of the cereal products that are nutritionally incomplete because of the deficiency in a few of essential amino acids (EAAs). Generally, lysine, tryptophan, and threonine are the essential amino acids present in very low level in cereals. Therefore, lysine, tryptophan, and threonine are said to be the limiting amino acid in wheat (Šramkova et al., 2009). On the contrary, wheat contains higher level of sulphur-containing amino acid like methionine and cysteine.

The replacement or the substitution of wheat flour in the instant noodles with other types of flour is getting more crucial as the addition of other types of flour into wheatbased products can helps in enhancing the quality of the product particularly in terms of nutritional aspect. Legume flour can be a good source of flour replacing or combining with the wheat flour as it provides sufficient proteins, complex carbohydrates, and some water-soluble vitamins and minerals (Sreerama et al., 2012). Chickpea (Cicer arietinum $L$.) is one of the most extensively consumed pulses worldwide especially in tropical and subtropical areas. Chickpea is regarded as one of the excellent sources of protein for consumption. The primary use of chickpea is for salad bars and blends with rice dishes in some countries like India. Chickpea and its flour or also known as garbanzo flour or besan are multipurpose due to its ideal cell wall polysaccharide composition, versatile flour functionality 
and relatively high content of oil. Apart from that, chickpea is foreseen to be the quick riser in the alternative and wheatfree flours for 2016 as more people opt for gluten-free flours made from legumes and nuts (Global Food Forums, 2015). To date, a number of studies have reported the utilization of chickpea flour to the baked products, cereal products and others (Noorfarahzilah et al., 2014).

In addition, as many as 14 million tonnes of okara generated annually worldwide particularly in Asian countries such as China, Japan, and Korea (Perez-Lopez et al., 2016). Despite the large amount of okara generated, it is seldom utilized by the industry due to the high water content $(80-85 \mathrm{~g} / 100 \mathrm{~g})$ and results in rapid deterioration of fresh okara (Park et al., 2015). Several studies have incorporated okara into food products to fortify the products with nutritious components to improve the textural properties as well as to extend the uses of okara. For instance, okara can be added directly to food for tempeh production (Jankowiak et al., 2014). Unfortunately, the acceptance of okara as a food product is limited due to the beany flavour exists in the product especially with the addition of fresh okara. Hence, usually most okara will eventually end up as animal feed or even waste (Jankowiak et al., 2014).

Okara as one of the fibre-rich by-product from the extraction of soymilk to produce mainly of soya drink and the tofu processing consisted of good water holding and emulsifying properties (Park et al., 2015). Okara is the insoluble part of the soybean after hot water extraction and contains predominantly fibres, protein, and fat (Jankowiak et al., 2014). There is $1.2 \mathrm{~kg}$ of fresh okara produced from $1 \mathrm{~kg}$ of soybean seed in tofu making. The health benefits of okara include high dietary fibre content with more insoluble dietary fibre, considerable protein content, fat, ash, isoflavones, and soybean oligosaccharides for instance stachyose and raffinose. In addition, okara is an ingredient that contributes to the regulation of metabolic disorders related to obesity, reduction of cancer risk, prebiotic, lipid metabolism, and so on (Perez-Lopez et al., 2016). In this study, the wheat flour was substituted by the proportions of chickpea and okara, and evaluated it effect on the organoleptic, physicochemical, cooking quality, nutritional, and storage quality of the noodles made therefrom.

\section{METHODS}

\section{A. Preparation of Chickpea and Okara Flours}

The chickpea bought from the local market in Kota Kinabalu, Sabah, Malaysia. The samples were grinded a few times using grinder to form chickpea flour. The chickpea and wheat flours were sieved with electronic sieve of 30 mesh. On the other hand, the okara obtained from the production of soymilk and soaked with water in the ratio of soybean and water of 1:8 for two hours. The soaked soybean was blended and put in a cotton bag to squeeze out the soymilk. The okara produced were then flattened on tray and dried in an oven at the temperature of $55 \pm 5^{\circ} \mathrm{C}$ overnight, grinded using grinder and sieved through 30 mesh sieve to produce okara flour and stored in the air-tight container (Porwal et al., 2014; Lu et al., 2013).

\section{B. Production of Instant Noodles}

The processing steps of the instant noodles in laboratory scale were modified the methods from Karim and Muhammad (2015) and Gulia et al. (2014). Whereas the ingredients used based on Porwal et al. (2014) and Lu et al. (2013) where wheat flour, chickpea flour, okara flour were weighed in range of $25-100 \%, 0-50 \%, 0-50 \%$ respectively and potato starch, salt and water were added in constant percentage at $10 \%, 1.6 \%$ and $52 \%$. All the flour ingredients were put into the mixer meanwhile the salt was pre-dissolved into the cold water and the salt solution was added gradually to the flours during mixing at slow speed in the mixer. Mixing was taken about one minute before scraping down the bowl and beater. After that, further mixing continued at high speed for around four minutes and stopped for two minutes at interval to scrap the bowl and beater. The dough formed was then covered by damp cloth and put in the container and rested for 15 minutes.

After resting, the flattened of the dough by the rolling pin with the plastic on the bottom of the dough to avoid the dough sticking on the surface of cutting board. The flattening of dough formed a dough sheet and passed through the rolls in the pasta machine to obtain uniform and desirable thickness. The sheets were passed through each roll with the roll gap of five, four and three, folded once, compounded and passed through the rolls again. After sheeting, the dough sheet was cut into the noodle strands with the slitter in the pasta machine.

The noodles strands were separated into smaller portion and scattered to avoid the strands from sticking together during steaming. Subsequently, the small portions of noodles were put into the electronic steaming machine and cooked the noodles by exposing the noodles to temperature of $100^{\circ} \mathrm{C}$ for three minutes. The steamed instant noodles were cooled under room temperature. The noodles were put into the frying basket and immersed in the oil with the temperature of $140-150{ }^{\circ} \mathrm{C}$ in the electric fryer for two minute for the purpose of deep frying. After the deep-frying process, the fried instant noodles were cooled to room temperature and packed in PP plastic to be stored in the airtight containers.

\section{Sensory Evaluation for Chickpea and Okara Composite Flours Instant Noodles}

Balanced Incomplete Block (BIB) test was carried out with 54 panellists from the students of Faculty of Food Science and Nutrition, Universiti Malaysia Sabah (FSMP, UMS) involved in the test as to screening test to select several samples with high ranks and proceed to the hedonic test to obtain the best formulation. Five samples were distributed to each panellist and the panellists ranked the samples from one to five with one as the first ranked sample and five as the sample with the fifth rank. Higher ranks samples in BIB test which possessed no significant 
difference between each other were selected to hedonic test to find out the best formulation. The hedonic test adopted was five-point Likert scale. The attributes to be evaluated by the participants during the hedonic test were colour, aroma, taste, texture and overall acceptance. There were 40 semitrained panellists from the Faculty of Food Science and Nutrition, University of Malaysia Sabah participated in the hedonic test to select the best formulation in terms of sensory properties and a questionnaire was given to the panellists.

\section{Physicochemical Tests for Chickpea and Okara Composite Flours Instant Noodles}

The candidates for the hedonic test were evaluated in terms of physicochemical properties like $\mathrm{pH}$, colour profile, tensile strength and Texture Profile Analysis (TPA) to select the best formulation from objective test. For $\mathrm{pH}$ test, five grams of the noodles were transferred into $20 \mathrm{ml}$ of distilled water. After that, the boiling of the samples was carried out for 10 minutes. Next, the $\mathrm{pH}$ was determined using a $\mathrm{pH}$ meter.

In addition, the colour profile of the instant noodles was determined by using Hunter Lab colour measuring machine which equipped with D65 illuminant with $2^{\circ}$ view angle and slit width of $2 \mathrm{~nm}$. Besides, the tensile strength of the instant noodles was determined using Texture Analyzer (TA.XT. PLUS) which was pre-calibrated using a $5 \mathrm{~kg}$ load cell. The settings involved in the tensile strength analysis were mode, measure force in tension, option, return to start, pre-test speed, $1 \mathrm{~mm} / \mathrm{s}$, test speed, $3.0 \mathrm{~mm} / \mathrm{s}$, post test speed, 10 $\mathrm{mm} / \mathrm{s}$ with the distance of $100 \mathrm{~mm}$ and the data acquisition rate of $200 \mathrm{pps}$. Firstly, the cooked noodles were placed in the room temperature for 10 minutes and tested by placing one end into the lower ring arm slot and the other to the upper arm. The tensile strength of the instant noodle strands was obtained from the result of Texture Analyzer.

Furthermore, Texture Profile Analysis (TPA) of the instant noodles was determined by Texture Analyser, TAXT2 (TA.XT. PLUS, United Kingdom) and equipped with the Texture Expert Exceed software package. The instrument was fitted with a $35 \mathrm{~mm}$ of cylinder probe. The sample was tested exactly after 10 minutes of cooking. Three noodles strands which cooked to optimal cooking time were placed as close to each other as possible and positioned centrally under the probe. Subsequently, the measurements were taken at room temperature using the calibration setting of $5 \mathrm{~kg}$ load cell with the return trigger path at $15 \mathrm{~mm}$. The measurement mode settings for the compression (pre-test, test and post-test) was set to a speed of $2.0 \mathrm{~mm} / \mathrm{sec}$ with the strain at $75 \%$ and the trigger type at auto-10 $\mathrm{g}$ and the data acquisition rate of $200 \mathrm{pps}$. The textural properties like hardness, adhesiveness, cohesiveness, springiness and chewiness were calculated using the results obtained from the texture analyzer. The hardness was the peak force of the first compression cycle of the graph obtained. Adhesiveness was the negative area for the first bite, which was defined as the work necessary to pull the compressing plunger away from the sample. On the other hand, cohesiveness was calculated using area positive for second cycle divided by first cycle. The values of springiness were obtained from the positive distance two divided by the positive distance one. Besides, chewiness was the product of hardness, cohesiveness and also the springiness.

\section{E. Cooking Quality Determination of Instant Noodles}

The instant noodles of the best formulation and the control instant noodles underwent cooking quality determination and compared the differences. The cooking quality determination methods of instant noodles were modified from Zawawi et al. (2014), Hou (2010), Park and Baik (2004). For the determination of optimal cooking time, $5.00 \pm 0.02 \mathrm{~g}$ of the instant noodles were cooked in $300 \mathrm{ml}$ of distilled water. A strand of the noodles was taken out every 10 seconds and place into the ambient temperature water immediately. The strand was squeezed between the two microscope slides. The instant noodles were considered to be fully cooked when the uncooked core cannot be seen in the noodle strands as well as the uniform colour and appearance was observed upon squeezing.

Other than that, for cooking yield determination, $150 \mathrm{ml}$ of distilled water was filled into a beaker and heated to boil by using hotplate. Around $10.00 \pm 0.02 \mathrm{~g}$ of instant noodles were weighed and cooked in the beaker according to optimal cooking time obtained previously and stirred continuously. The beakers were covered by aluminium foil during cooking process to avoid the water evaporation from occurring. After the optimal cooking time, the cooked noodles were separated from the cooking water and cooled for 15 minutes. The cooked instant noodles were weighed and the cooking yield was calculated using equation below:

$$
\text { Cooking yield }(\%)=\frac{\text { Weight of noodles after cooking }}{\text { Weight of noodles bef ore cooking }} \times 100
$$

Furthermore, for rehydration determination, the instant noodles were soaked in boiling water within the optimal cooking time obtained previously. After the soaking time was up, the noodles were drained onto the sieve for two minutes without shaking and then weighed. The calculation of the rehydration rate is as in equation shown:

Rehydration rate, $\%=$ (weight of drained noodles-weight of dry noodles) $x 100$ weight of dry noodles

Moreover, for cooking loss determination, the cooking water from the cooking yield method mentioned above was separated and poured into $250 \mathrm{ml}$ of volumetric flask. Then, the distilled water was poured into the volumetric flask until the mark and shaken to homogenize the cooking water solution. The crucible was weighed beforehand. After that, $10 \mathrm{ml}$ of the solution was pipetted into a dried crucible and left to dry to a constant weight in the oven at $105^{\circ} \mathrm{C}$. The solid loss during the cooking, cooking loss was calculated by equation depicted below: 
Cooking loss $(\%)=\frac{A-B}{\text { Noodle sample weight }-c} \times 25$

Where, $a$ is the weight of crucible + dry cooked water sample

$\mathrm{b}$ is the weight of crucible

$\mathrm{c}$ is the noodles moisture content

\section{F. Proximate Analysis of the Instant Noodles}

The control and instant noodles of best formulation were prepared and broken into small pieces manually and stored in an airtight container for triplicated proximate analysis. All proximate composition which included the moisture content, ash, crude fat, protein, crude fibre and total carbohydrates were determined according to AOAC (2000), AACC (2000), Daniel et al. (2014), Shin et al. (2013) and Hakoda et al. (2006).

\section{G. Total Dietary Fibre and Energy Content Analysis}

Total dietary fibre content for the control samples of instant noodles and samples of the best instant noodles formulation were determined by Huang et al. (2013). The energy content of both the sample of best instant noodles formulation and control sample of instant noodles were determined using the following equation from Barros et al. (2010).

$$
\begin{aligned}
& \text { Energy }(\mathrm{kcal})=(\mathrm{C} \times 4)+(\mathrm{P} \times 4)+(\mathrm{F} \times 9)+(\mathrm{D} \times 2) \\
& \text { Where, } \\
& \qquad \begin{array}{l}
\mathrm{C}=\text { Carbohydrate weight }(\mathrm{g}) \\
\mathrm{P}=\text { Protein weight }(\mathrm{g}) \\
\mathrm{F}=\text { Fat weight }(\mathrm{g}) \\
\mathrm{D}=\text { Total dietary fibre weight }(\mathrm{g})
\end{array}
\end{aligned}
$$

\section{H. Accelerated Shelf Life Test}

The best formulation of the instant noodles underwent the accelerated shelf life study as to estimate the quality of the instant noodles during the accelerated shelf life period. The instant noodle samples were packed in polypropylene plastic sealed and stored in the airtight container to be put in an incubator for eight months at $45 \pm 2^{\circ} \mathrm{C}$.

The determination of the water activity of best formulated instant noodles was conducted by using the water activity meter. Around $2 \mathrm{~g}$ of the samples were put in the water activity meter and the results were obtained after five minutes. Besides, physicochemical tests were performed on the best formulated instant noodles during the accelerated shelf life study test. With the physicochemical tests, the quality of the instant noodles was assessed and monitored throughout the period.

The microbiological tests were carried out and the method modification from Ceylan (2006). Potato dextrose agar (PDA) and plate count agar (PDA) were used for the enumeration of bacteria, yeast and mold. Two techniques pour plating and spread plating was used for the enumeration. In addition, paired t-test was used in the sensory evaluation of the instant noodles' storage qualities. The sensory attributes of the instant noodles in terms of taste, colour, texture and others were evaluated with seven scales with one indicated inferior largely to $\mathrm{R}$ and seven was superior largely to $\mathrm{R}$ and there were 40 panellists participated in the sensory evaluation every month.

\section{Statistical Analysis}

Statistical Analysis. All th datas obtained proximate analysis, total dietary fibre, physicochemical tests and sensory evaluation tests were analysed using IBM Statistical Package for the Social Sciences (SPSS) Statistics version 21. All datas obtained from the sensory evaluation in the accelerated shelf life study, Kruskal- Wallis and post-hoc test, Mann Whitney were utilized by using variant one way ANOVA and post hoc Tukey test with $95 \%$ confidence level which showing significant difference of $(p<0.05)$ for all the atributes tested.

\section{RESULTS AND DISCUSSION}

\section{A. Sensory properties of Instant Noodles from Chickpea and Okara Composite Flours}

The formulations were divided into three groups based on the significant differences. Control, F1, F3, F4, and F6 possessed no significant difference $(p>0.05)$ between each other with the rank sum of $45,45,51,51$, and 66 respectively and categorized in the same group as the rank sum differences did not exceed 21.47 as shown in Table 1. The same went to F2, F5 and F7, F8, F9 with the value of 87,96 and 111,123 and 135 respectively. Control is the formulation that most preferred by the panellists. This may be attributed to the similar characteristic of the control with the commercial instant noodles and therefore, the panellists are more familiar with the formulation in terms of colour, texture and so on.

Furthermore, the replacement of the wheat flour above $50 \%$ affected the preference of the panellists markedly as illustrated in the table. The possible explanation may be due to the wheat flour determines the distinctive qualities and characteristics of the commercial instant noodles. The decrease of the percentage of wheat flour for more than $50 \%$ may cause the noticeable differences in terms of colour, texture, aroma and taste. Apart from that, it can be observed that formulations with the presence of chickpea flours in the instant noodles received highly favourable ranks. This may be explained by the unique nutty flavour of chickpea and enhances the flavour of the instant noodles. Five formulation namely control, F1, F3, F4, and F6 were brought to hedonic sensory test to select the best formulation in terms of sensory properties due to no significant difference between them.

TABLE 1: RANK SUM OF ALL FORMULATIONS

\begin{tabular}{|c|c|}
\hline Formulations & Rank sum \\
\hline Control & $45^{\mathrm{a}}$ \\
\hline F1 & $45^{\mathrm{a}}$ \\
\hline F3 & $51^{\mathrm{a}}$ \\
\hline
\end{tabular}


TABLE 1. CONT

\begin{tabular}{|c|c|}
\hline F4 & $51^{\mathrm{a}}$ \\
\hline F6 & $66^{\mathrm{ab}}$ \\
\hline F2 & $87^{\mathrm{b}}$ \\
\hline F5 & $96^{\mathrm{b}}$ \\
\hline F7 & $111^{\mathrm{c}}$ \\
\hline $\mathrm{F} 9$ & $123^{\mathrm{c}}$ \\
\hline F8 & $135^{\mathrm{c}}$ \\
\hline
\end{tabular}

Control, F1, F3, F4 and F6 were chosen for the hedonic sensory test to select the best formulations as they did not possess any significant difference between them. The five formulations mentioned above were evaluated from the organoleptic properties like taste, aroma, colour, texture and overall acceptance. Figure 1 illustrates that the results for hedonic sensory test and each attribute was discussed individually.

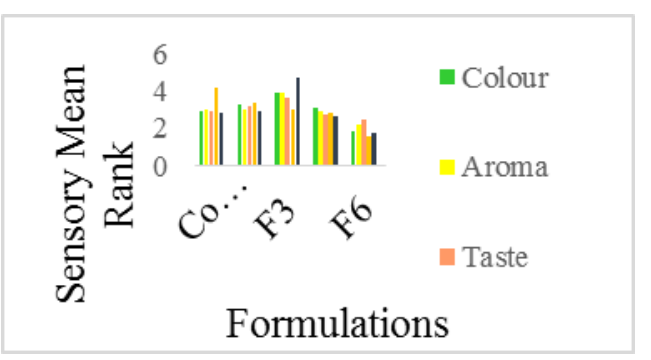

Fig 1: Sensory mean score of five formulations of instant noodles

As for the taste of the instant noodles, there were no significant differences of the mean rank between control (2.95), F1 (3.25), and F4 (3.08) and possessed significant differences between the three formulations mentioned above with F3 (3.90) and F6 (1.82). The results are as above might be due to F3 was the formulation with the combination of three flours in lower amount, and the special compounds present in chickpea and okara which are phenolic compounds contribute to the unique taste of flours ( $\mathrm{Li}$ et al., 2013; Aguilera et al., 2009). Meanwhile, the possible explanation for lowest mean rank of F6 might be F6 which had higher percentage of chickpea and okara flours caused the astringency and the bitterness attributed to high level of phenolic compounds (Robbins, 2003). In terms of aroma, significant difference existed between the mean rank of F3 (3.89) and F6 (2.24) with control (2.98), F1 (2.98) and F4 (2.92). The combination of the aroma of three types of flours with lower percentage gained more popularity than that with higher percentage and the possible explanation may be both okara and chickpea possess their own distinctive aroma and therefore enhance the aroma of the plain instant noodles. The lowest mean rank of F6 indicated that the panellists are not able to accept the replacement of wheat flour in instant noodle with too high percentage. These results match those observed in studies by Lu et al. (2013).

For the colour of the instant noodles, the results in Figure 1 depicted that significant difference existed between
F3 and control, F1, F4 and F6. The preference of the panellist ranked from F3 (3.65), F1 (3.18), control (2.95), F4 (2.76) to F6 (2.45). The results of sensory rank of F4 and F6 might be due to the unattractive dark cooked colour which attributed to the colour of chickpea and okara flours. The results are consistent with the data obtained in the study by Omeire et al. (2015), Porwal et al. (2014) and Lu et al. (2013) as the increase in the replacement of wheat flour decreased the sensory scores of the noodles due to the declined in the palatability of the instant noodles. The preference of consumers on the bright yellow translucent noodles according to Ugarcic-Hardi et al. (2003) and Madhumitha and Prabhasankar (2011) may be the reason of $\mathrm{F} 3$ received the highest mean rank for colour attribute. Both chickpea and okara flours contribute to the yellowness of the flours.

There were significant differences between the mean rank of control instant noodles' texture, F6 and F1, F3 and F4. Control attained the highest mean rank, 4.20 and followed by F1 (3.41), F3 (2.99), F4 (2.80) and F6 (1.60). The highest mean score of texture for control instant noodles was attributed to the elasticity of the noodles due to the formation of gluten network. High protein content of flours not only causes hardness of the noodles to incline but also decrease the surface smoothness of the noodles based on the studies reported by Hou et al. (2013). In terms of overall acceptance, there were significant differences between control (2.84), F1 (2.95), F4 (2.70) and F3 (4.71) as well as F6 (1.79). From the results presented in Figure 3.2, it can be observed that the addition of the non-traditional flours like chickpea and okara flour did not adversely affect the acceptability of the instant noodles with F3 gained the highest mean rank compared to control which ranked third in the overall acceptance.

\section{B. Physicochemical Properties of Chickpea and Okara Composite Flours Instant Noodles}

There were several physicochemical aspects evaluation for the formulations in hedonic sensory test namely $\mathrm{pH}$, colour profile, tensile strength, and texture profile analysis (TPA). Table 2 shows that the $\mathrm{pH}$ values of the five formulations of chickpea and okara composite flour instant noodles.

TABLE II: PH AND COLOUR VALUES OF FIVE FORMULATIONS OF CHICKPEA AND OKARA COMPOSITE FLOUR INSTANT NOODLES

\begin{tabular}{|l|c|l|l|l|}
\hline \multirow{2}{*}{$\begin{array}{l}\text { Formul } \\
\text { ation }\end{array}$} & \multirow{2}{*}{$\mathbf{p H}^{\mathbf{1 2}}$} & \multicolumn{3}{|c|}{ Colour value } \\
\cline { 3 - 5 } & & \multicolumn{1}{|c|}{$\mathbf{L}^{\text {112 }^{2}}$} & \multicolumn{1}{|c|}{$\mathbf{a}^{*^{12}}$} & \multicolumn{1}{|c|}{$\mathbf{b}^{\text {12 }^{2}}$} \\
\hline Control & $6.89 \pm$ & $75.16 \pm$ & $5.75 \pm$ & $32.39 \pm$ \\
& $0.08^{\mathrm{a}}$ & $0.06^{\mathrm{a}}$ & $0.14^{\mathrm{a}}$ & $0.11^{\mathrm{a}}$ \\
\hline F1 & $6.80 \pm$ & $73.97 \pm$ & $6.53 \pm$ & $33.01 \pm$ \\
& $0.04^{\mathrm{a}}$ & $0.03^{\mathrm{c}}$ & $0.02^{\mathrm{b}}$ & $0.01^{\mathrm{b}}$ \\
\hline F3 & $6.41 \pm$ & $72.29 \pm$ & $7.15 \pm$ & $33.95 \pm$ \\
& $0.02^{\mathrm{b}}$ & $0.12^{\mathrm{c}}$ & $0.08^{\mathrm{c}}$ & $0.05^{\mathrm{c}}$ \\
\hline F4 & $6.24 \pm$ & $70.87 \pm$ & $8.05 \pm$ & $34.74 \pm$ \\
& $0.05^{\mathrm{c}}$ & $0.32^{\mathrm{d}}$ & $0.28^{\mathrm{d}}$ & $0.12^{\mathrm{d}}$ \\
\hline F6 & $6.13 \pm$ & $70.23 \pm$ & $8.73 \pm$ & $35.70 \pm$ \\
& $0.06^{\mathrm{d}}$ & $0.73^{\mathrm{d}}$ & $0.11^{\mathrm{e}}$ & $0.42^{\mathrm{e}}$ \\
\hline
\end{tabular}

${ }^{\mathrm{l}}$ Values are stated as mean \pm standard deviation, $\mathrm{n}=5$

${ }^{2}$ Values in the same column with different superscript letters are significantly different $(p<0.05)$ 
There were significant difference between each sample except for control and F1. Although the wheat flour replacement of F1 and F3 was the same, 25\% but there was significant difference between F3 and control as compared to F1. These results are consistent with the data reported by Wickramarathna and Arampath (2003) and increase in the $\mathrm{pH}$ of the bakery product with okara flours as compared to the control bakery product. The possible explanation for this might be due to the presence of okara flours in F3. Soybean is rich in phenolic compounds, phenolic acids and flavonoids according to previous studies (Li et al., 2013; Lee et al., 2005). The chickpea also contains high level of phenolic acid but the normal processing procedures like cooking and soaking decreases the total phenolic content of chickpea as compared to soybean. Therefore, the phenolic content of chickpea flour will be less than okara flour after the steaming and frying of noodles (Duenas et al., 2012). Table 3 portrayed the Hunter Lab colorimetric values of the instant noodles. It is interesting to note that all five formulations of the test possessed significant difference in values of $\mathrm{L}^{*}, \mathrm{a}^{*}$ and $\mathrm{b}^{*}$. Control instant noodles had the highest brightness, $75.16 \pm 0.06$. The result is in line with the study reported the $\mathrm{L}^{*}$ value of commercial instant noodles in Malaysia range from 75.14 to 82.90 (Chowdhury et al., 2011). A possible explanation for the result is due to the presence of polyphenol oxidase (PPO) in wheat flour (Anderson and Morris, 2001).

The trend of reducing brightness of the instant noodles can be observed as going down the column, from 70.23 to 73.97. The replacement of wheat flour was the same for F1 and F3 as well as F4 and F6. The lower brightness of F3 and F6 as compared to their counterparts, F1 and F4 might be because of the presence of okara flours. Both chickpea and okara flours have high level of protein content with higher protein content in okara, $27 \%$ than in chickpea, 21.70-23.40\% (Li et al., 2013; Alajaji and ElAdawy, 2006) and induce more maillard reaction. Other than that, ash content of the flours also affects the brightness of the instant noodles. Chickpea and okara are regarded as good source of minerals like potassium, iron, calcium and others. (Li et al., 2013; Alajaji and El-Adawy, 2006). Moreover, as for $\mathrm{a}^{*}$ and $\mathrm{b}^{*}$ values the increasing trend can be seen in the Table 3 from control to F6. The results might be explained with the increasing protein content of the formulations. The reason of the inclination of redness and yellowness of the instant noodles is because of the nitrogen fertilization (Wang and Daun, 2004). The significant difference between each formulation might be attributed to the notable differences between the protein content of each formulation.

The results of the tensile strength of the five formulations were summarized in the Table 4 . There were significant difference between the tensile strength of each formulations. The possibility of the decreasing trend in tensile strength going down the column is due to the diluting effect of the gluten protein in the wheat flour as a result of partial substitution with the chickpea and okara flour. Li et al., 2013 reported that gluten occupies $80 \%$ of the total protein in wheat flour. The strength of the dough made up of wheat flour depends on the gliadins and glutenins. Thus, the replacement of the wheat flour impairs the gluten matrix and weakened the structure of the noodles (Ritthiruangdej et al., 2011). The results were consistent with the study suggested by Foo et al. (2011) where the tensile strength yellow alkaline noodles decreased with the increase substitution of the banana flours.

The results of texture profile analysis (TPA) of five formulations are presented in Table. There were significant difference $(\mathrm{p}<0.05)$ in the hardness, adhesiveness, cohesiveness, springiness and chewiness of the each formulation. The study found that the hardness of the noodles increased with the increased of the wheat flour replacement from $26.00 \mathrm{~N}$ to $43.05 \mathrm{~N}$. The main reason contribute to the increase in the hardness is increased protein content and decreased water uptake (Hou, 2001; Park and Baik, 2004) as for the adhesiveness of the instant noodles.

TABLE III: TENSILE STRENGTH AND TEXTURE PROFILE ANALYSIS (TPA) OF INSTANT NOODLES

\begin{tabular}{|c|c|c|c|c|c|c|}
\hline $\begin{array}{l}\text { Form } \\
\text { ulatio } \\
\text { n }\end{array}$ & $\begin{array}{l}\text { Tensile } \\
\text { strength } \\
\text { (g) }{ }^{12}\end{array}$ & $\begin{array}{l}\text { Hardne } \\
\text { SS } \\
\text { (N) }{ }^{12}\end{array}$ & $\begin{array}{c}\text { Adhesiven } \\
\text { ess } \\
(\mathrm{g} \cdot \mathrm{sec})^{12}\end{array}$ & $\begin{array}{c}\text { Cohesiv } \\
\text { eness } \\
\text { Ratio }^{12}\end{array}$ & $\begin{array}{c}\text { Springin } \\
\text { ess } \\
(\mathrm{mm})^{12}\end{array}$ & $\begin{array}{l}\text { Chew } \\
\text { iness } \\
(\mathrm{N} \cdot \mathrm{m} \\
\mathrm{m})^{12}\end{array}$ \\
\hline $\begin{array}{l}\text { Contr } \\
\text { ol }\end{array}$ & $\begin{array}{c}46.25 \pm \\
0.82 \mathrm{a}\end{array}$ & $\begin{array}{c}26.00 \pm \\
0.73^{\mathrm{a}}\end{array}$ & $\begin{array}{c}-0.18 \pm \\
0.01^{\mathrm{a}}\end{array}$ & $\begin{array}{c}0.83 \pm \\
0.02^{\mathrm{a}}\end{array}$ & $\begin{array}{c}1.04 \pm \\
0.03^{\mathrm{a}}\end{array}$ & $\begin{array}{c}22.69 \\
\pm \\
0.91^{\mathrm{a}}\end{array}$ \\
\hline $\mathrm{F} 1$ & $\begin{array}{c}34.21 \pm \\
0.91 b\end{array}$ & $\begin{array}{c}28.52 \pm \\
0.97^{\mathrm{b}}\end{array}$ & $\begin{array}{c}-0.17 \pm \\
0.01^{\mathrm{a}}\end{array}$ & $\begin{array}{c}0.71 \pm \\
0.02^{\mathrm{b}}\end{array}$ & $\begin{array}{c}0.92 \pm \\
0.03^{\mathrm{b}}\end{array}$ & $\begin{array}{c}18.68 \\
\pm \\
0.88^{b}\end{array}$ \\
\hline F3 & $\begin{array}{c}22.79 \pm \\
0.38 \mathrm{c}\end{array}$ & $\begin{array}{c}34.16 \pm \\
0.73^{c}\end{array}$ & $\begin{array}{c}-0.14 \pm \\
0.01^{\mathrm{b}}\end{array}$ & $\begin{array}{c}0.60 \pm \\
0.01^{\mathrm{c}}\end{array}$ & $\begin{array}{c}0.82 \pm \\
0.02^{\mathrm{c}}\end{array}$ & $\begin{array}{c}16.93 \\
\pm \\
0.21^{\mathrm{c}} \\
\end{array}$ \\
\hline $\mathrm{F} 4$ & $\begin{array}{c}17.16 \pm \\
1.82 \mathrm{~d}\end{array}$ & $\begin{array}{c}38.05 \pm \\
0.54^{\mathrm{d}}\end{array}$ & $\begin{array}{c}-0.12 \pm \\
0.01^{\mathrm{c}}\end{array}$ & $\begin{array}{c}0.52 \pm \\
0.03^{\mathrm{d}}\end{array}$ & $\begin{array}{c}0.69 \pm \\
0.02^{\mathrm{d}}\end{array}$ & $\begin{array}{c}13.61 \\
\pm \\
0.02^{\mathrm{d}}\end{array}$ \\
\hline F6 & $\begin{array}{c}10.34 \pm \\
0.58 \mathrm{e}\end{array}$ & $\begin{array}{c}43.05 \pm \\
0.79^{\mathrm{e}}\end{array}$ & $\begin{array}{c}-0.10 \pm \\
0.01^{\mathrm{d}}\end{array}$ & $\begin{array}{c}0.47 \pm \\
0.02^{\mathrm{d}}\end{array}$ & $\begin{array}{c}0.56 \pm \\
0.02^{\mathrm{e}}\end{array}$ & $\begin{array}{c}11.18 \\
\pm \\
0.40^{\mathrm{e}}\end{array}$ \\
\hline
\end{tabular}

produced, the increased adhesiveness of the instant noodles with more addition of composite flour with the value $0.18 \mathrm{~g} \bullet \mathrm{sec}$ to $-0.10 \mathrm{~g} \bullet \mathrm{sec}$. This is caused by the water absorption ability of different ingredients. Less water utilized in making pre-gelatinization of the flour will produce more adhesive noodles according to previous studies (Miyazaki et al., 2004). Okara which has content more water because of strong water absorption capability owing to high dietary fiber results in less water absorbed during cooking process of the instant noodles.

Apart from that, the cohesiveness of the instant noodles decreased from 0.83 (control instant noodles), to 0.47 (F6). The blend of okara and chickpea flours cause the noodles to have less gluten content and result in less formation of strong cross-link of glutenin and gliadin within the molecules. As a result, the reduced cohesiveness causes the noodles with more chickpea and okara flours can be separated apart compared to control. Besides, the springiness of the instant noodles decreased from control to 
F6 which the incorporation of the chickpea and okara flour increased. Both chickpea and okara are gluten-free ingredients (Minarro et al., 2012). Thus, the gluten diluting effect will reduces the springiness of the instant noodles. Furthermore, chewiness of the instant noodles also decreased from control to F6 from $1.04 \mathrm{~mm}$ to $0.56 \mathrm{~mm}$. It relies primarily on hardness rather than cohesiveness and springiness. The chewiness is inversely proportional to the hardness of the product (Bourne, 2002).

\section{Cooking qualities of the best and control instant noodles}

F3 which comprised of $75 \%$ of wheat flour, $12.5 \%$ of chickpea flours and $12.5 \%$ of okara flours was selected as the best formulation due to highest mean rank in nearly all the sensory attributes among the panellists and satisfactory results in physicochemical tests. The cooking qualities of the best and control instant noodles in terms of optimal cooking time, cooking yield, rehydration and cooking loss. F3 had significantly longer optimal cooking time where $\mathrm{p}<0.05$ with $5.07 \pm 0.06$ minutes in F3 than control, $4.20 \pm$ 0.61 minutes and the result was in agreement with findings from Purwandari et al. (2014) and Park and Baik (2004). Additionally, according to Park and Baik (2004), higher protein content leaded to longer optimum cooking time and F3 had higher protein content by virtue of chickpea and okara flours incorporation. The more proteins which surround the starch granules cause them to swell and gelatinize slower. The cooking yield of F3 also significantly higher than control $(\mathrm{p}<0.05), 219.58 \pm 0.80 \%$ as compared to $203.10 \pm 1.61 \%$ due to higher ash content of flour proved to have relation for the cooking gain rate during cooking process (Polesi et al., 2011; Jankowiak et al., 2014). Moreover, the higher amylose content of the chickpea and okara blended flour results in higher level of amylose network swelling during the boiling process of instant noodles.

Rehydration rate of F3 is lower than control, $97.22 \pm$ $0.20 \%$ and $98.35 \pm 1.90 \%$ respectively. The external and internal porous structures will influence the rehydration rate of the noodles (Gulia et al., 2014). The firmer structure of F3 attributed to higher protein content as compared to control hinders the rehydration rate and thus, the rehydration rate is lower in F3. Moreover, the cooking losses of F3 also significantly more than control $(\mathrm{p}<0.05)$ which is $0.04 \pm$ $0.01 \%$ as compared to $0.03 \pm 0.01 \%$ of control. Based on the result gained, the cooking quality of the control is better than F3 due to lesser cooking loss. The result might be explained by the unique capability of the wheat flour to form gluten matrix upon the mixture with water and therefore hold the noodles together (Torres et al., 2007; Jayasena et al., 2010; Aydin and Gocmen, 2011). Furthermore, the addition of okara flours into the instant noodles rose up the cooking loss due to the gluten cannot hold too much of the dietary fiber particles and result in some fibre dissolved in water during the cooking process (Lu et al., 2013).

\section{Nutrient Composition of the Best Mango Seed Kernel Instant Noodles}

- Proximate Composition

The proximate composition comprised of moisture content, ash content, protein content, crude fat content, crude fibre content and total carbohydrates were performed for control and F3. There were significant difference $(p<0.05)$ between all the nutrient compositions of control and F3.

As for the moisture content of the instant noodles, F3 had higher moisture content, $3.51 \pm 0.78 \%$ than control $1.54 \pm 0.14 \%$. The result is consistent with the data obtained in study by Dewi (2011) where higher moisture content was examined in the samples as compared to control. The oil absorption ability of the control is better than F3 attributed to the lower protein content (Jayasena et al., 2010). This causes the reduced moisture content and increased fat content of the control as compared to F3. Moreover, the ash content of control and F3 differ significantly $(\mathrm{p}<0.05)$ with more ash content in F3, $1.76 \pm 0.12 \%$ as compared to $1.06 \pm 0.46 \%$ in control. Chickpea provides various minerals according to Jukanti et al. (2012). Iron is the mineral with the highest concentration in chickpea. Furthermore, the boiling process also did not affect much on the concentration of the macro-elements like calcium, magnesium and micro-element like iron and zinc in $\mathrm{mg} / 100 \mathrm{~g}$ dry weight basis according to Alajaji and El-Adawy (2006).

The protein content of F3, $11.97 \pm 0.04 \%$ is significantly higher $(\mathrm{p}<0.05)$ than control $10.01 \pm$ $0.81 \%$. Chickpea is regarded as rich source of protein and consists of three times more proteins content than cereals like wheat (Hefnawy et al., 2012). Chickpea contains $17-22 \%$ of protein before and $25.3-28.9 \%$ after dehulling according to the findings published by Jukanti et al. (2012) and Hefnawy et al. (2012). Moreover, chickpea and okara also rich in essential amino acids like lysine, phenylalanine, valine, threonine, methionine, and thus, it is a perfect complement for wheat flour or as a good source of plant protein. In addition, the crude fat content of F3, $18.84 \pm 0.08 \%$ is significantly lower $(\mathrm{p}<0.05)$ than control, $21.33 \pm 1.40 \%$. The result was in line with the study reported by Jayasena et al. (2010). The protein content and the quality of the flour are the factor influencing the oil absorption of the product. On the contrary, the noodles from the high protein flours manufacture instant noodles with low levels of free lipids because of the formation of the compact noodle surface structure in the midst of the steaming process of the noodles (Gazmuri and Bouchon, 2009; Park and Baik, 2004).

The crude fiber content of F3 is significantly higher $(\mathrm{p}<0.05)$ than control, which are $2.49 \pm 0.04 \%$ as compared to $0.61 \pm 0.31 \%$. This result matches with the study by Kaur et al. (2013) whereby the 
replacement of wheat flour with okara flour increased the crude fiber of the pasta. Okara is a great source of fiber (Li et al., 2013). Besides, chickpea also composed of high content of fiber according to the previous study by Khan et al. (2007). The total carbohydrates of F3, $53.87 \pm 0.57 \%$ is significantly less $(\mathrm{p}<0.05)$ than control, $63.75 \pm$ $0.96 \%$ as illustrated in Table 6 . The reason of the lower content of carbohydrates of F3 compared to control due to the increased of other nutritional compositions of F3 and the total carbohydrates was calculated by differences. Since the carbohydrates content of the wheat flour is high, hence there is necessity to substitute with okara flour which contains low carbohydrate content and high in other nutrients.

\section{- Energy Content and Total Dietary Fibre}

The energy content determination depends on the food components that provide energy like protein, fat, dietary fiber, carbohydrates. The energy content of the control and F3 differ significantly $(\mathrm{p}<0.05)$ with more energy content in control, $498.40 \mathrm{kcal}$ than F3, 453.27kcal with reduction of $9.05 \%$ as compared to control sample. The main contributor to the significant difference between the energy content of control and F3 is significantly higher crude fat content and carbohydrates analysed. On the other hand, the significantly higher $(\mathrm{p}<0.05)$ dietary fiber content in F3, $10.05 \mathrm{~g} / 100 \mathrm{~g}$ can be observed in Table 6 , as compared with $2.31 \mathrm{~g} / 100 \mathrm{~g}$ in control. Besides, the result is in agreement with the finding by Kumar and Prabhasankar (2015) whereby the dietary fiber content in terms of soluble dietary fiber and insoluble dietary fiber of the instant noodles increased with the addition of pea flour which is also one of the legume flours like chickpea flour. The dietary content of chickpea is $18-22 \mathrm{~g}$ per $100 \mathrm{~g}$ and it is regarded as pulses that contain high level of dietary fiber. Besides, the okara is rich in cellulose which is the insoluble fiber that can helps in the fermentation of the microbes in large intestine. The dietary fiber of the okara is as much as twice of the soybean as suggested by Recundo-Cuenca et al. (2008).

\section{E. Accelerated Shelf Life Quality of the Instant Noodles}

Accelerated shelf life study consists of the examination of water activity, physicochemical properties namely texture profile analysis, colour profile, tensile strength and $\mathrm{pH}$, microbiological test and sensory properties were conducted.

\section{- Water activity of Stored Instant Noodles}

The water activity of the stored instant noodles had been evaluated every month using the water activity meter and the results are presented in Figure 2. From Figure 2, the increasing trend of water activity can be observed over the eight months of storage period from 0.243 to 0.396 . There was significant difference $(\mathrm{p}<0.05)$ for every month starting sixth month. In contrast with the earlier studies with the water activity of 0.50 , the water activity of the instant noodles was 0.243 in the first month. The possible explanation for this result is because of the elevated storage temperature which was $45 \pm 2^{\circ} \mathrm{C}$. Syamaladevi et al. (2016) suggested that the significant reduction of water activity occurred when the increase in temperature particularly with the fat-rich products and this may be attributed to the elevation of the solubility of the non-polar solids such as fat in water at higher temperature. Besides, the gradual increase of the water activity along the storage period from the first month to fifth month can be observed. The sharp increase of water activity may be related to the appreciably increase in the moisture content. F3 contains considerably high fat and it leads to the rapid moisture absorption from the environment (Chowdhury et al., 2011).

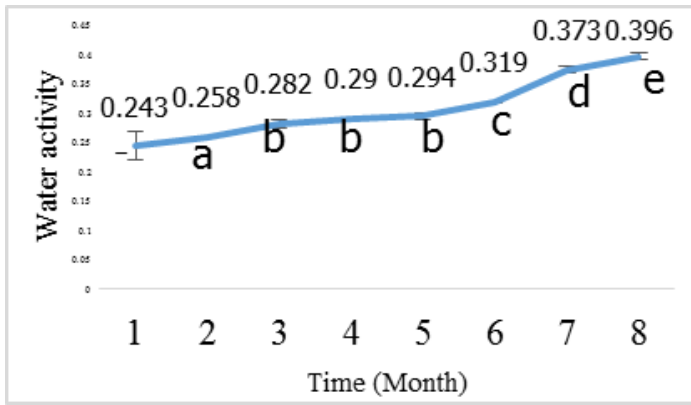

Fig. 2: Water activity of the instant noodles of best formulation in eight months

\section{- Physicochemical Tests}

Physicochemical tests were subjected to the stored instant noodles over eight months and the quality of the noodles was evaluated in terms of $\mathrm{pH}$, colour and also texture. The $\mathrm{pH}$ of the instant noodles was examined every month during the storage period and the results were presented in Figure 3

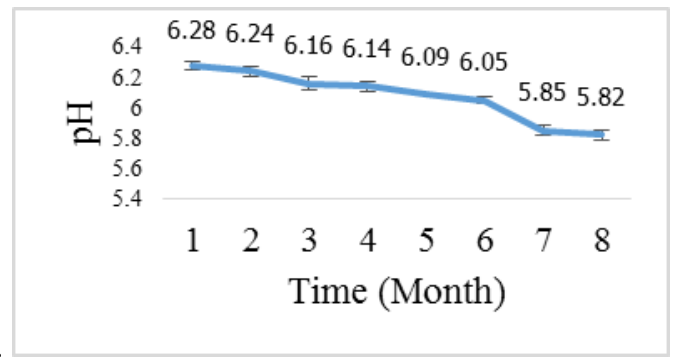

Figure 3: $\mathrm{pH}$ of instant noodles of best formulation along eight months

From Figure 3, the decreasing trend of $\mathrm{pH}$ can be seen from 6.28 to 5.82 with significant difference $(\mathrm{p}<0.05)$ for almost every two months. The noodles shifted to more acidic over the storage period. This may be explained by the activity of the microorganisms. F3 is rich in carbohydrates, proteins and fats. Besides fats as a source of energy, amino 
acids also provides nitrogen and energy to be utilized by the microorganisms and therefore induce the production of acids and decrease the $\mathrm{pH}$ of the noodles.

The effect of the storage on the colour change of the instant noodles was observed and Figure 4, 5 and 6 provide the results obtained from the colour profile analysis using HunterLab. The trend of decreasing brightness, increasing redness, and increasing yellowness can be seen along the eight months of storage. The brightness of the noodles decreased from 75.46 to 66.56 . The results seem to be consistent with the finding reported by $\mathrm{Li}$ et al. (2017) and Asenstorfer et al. (2009), whereby the noodles surface was turn to darker observed during the storage of period. The possible explanation is the presence of polyphenol oxidase (PPO) as one of the causes to the reduced brightness of the noodles (Asenstorfer et al., 2014). The quinone products of the PPO from the previous reaction will react with several functional groups like phenolic, amines and others. Chickpea and okara composite flour which is abundant with phenolic compounds form complex coloured products, melanins over the storage period (Fuerst et al., 2006).

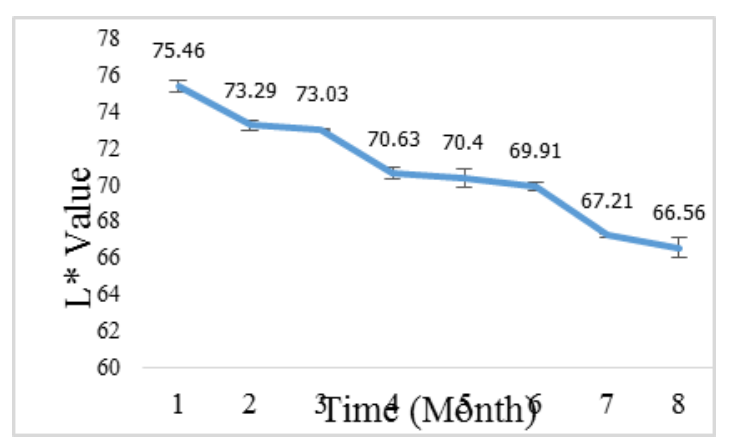

Figure 4: $\mathrm{L}^{*}$ value of instant noodles of best formulation along eight months

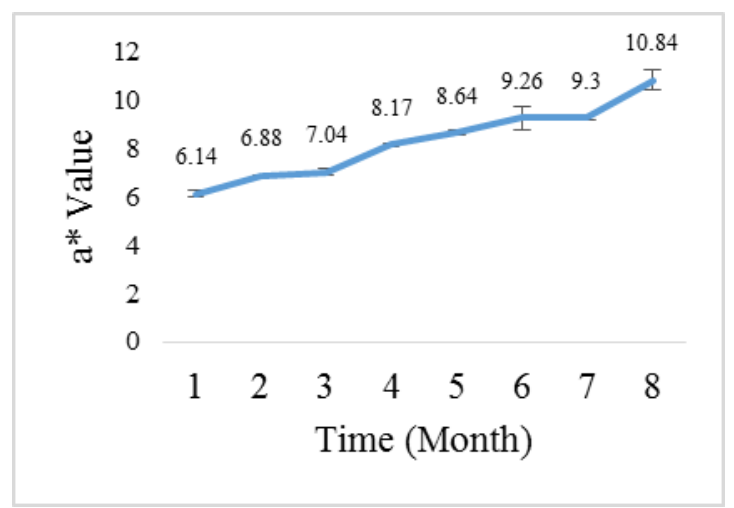

Figure 5: $a^{*}$ value of instant noodles of best formulation along eight months

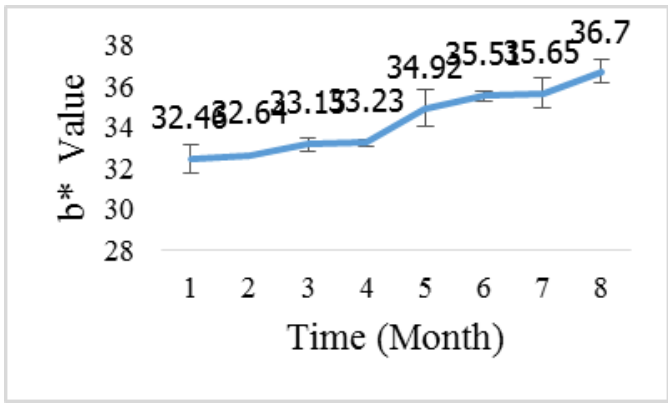

Figure 6: $b^{*}$ value of instant noodles of best formulation along eight months

The stored instant noodles were evaluated in terms of tensile strength every month over eight months of accelerated shelf life study. Figure 7 depicts the tensile strength of the instant noodles in $\mathrm{g}$.

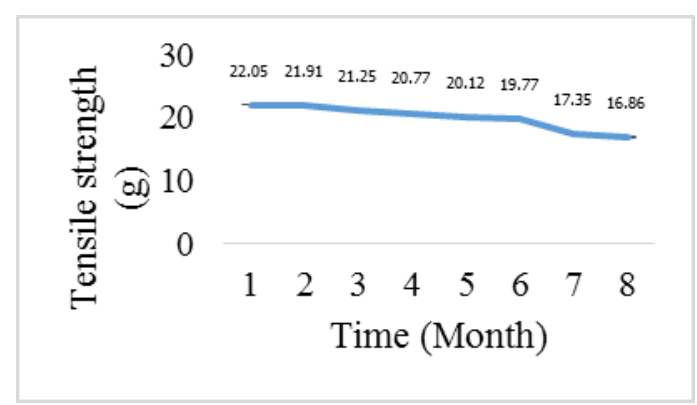

Figure 7: Tensile strength of instant noodles of best formulation along eight months

Based on Figure 7, the tensile strength of the noodles decreased from 22.05 to 16.86 and interestingly, the tensile strength of the noodles possessed significant difference $(\mathrm{p}<0.05)$ every month starting from second month. The results were in agreement with the finding of Thomas et al. (2014) where the rice noodles reduced its tensile strength significantly after undergone storage. The amylose content is said to have effect on the strength of the noodles. The aging process during storage leads to the decrease of the amylose content in the noodles and cause the reduction of the tensile strength due to the amylose content is directly proportional to the the tensile strength (Fari et al., 2011; Guo et al., 2003).

The texture properties of the noodles experienced changes along eight months of storage period. The results of textural properties were summarized in Table 4 . The trend of hardness of the noodles increased across the storage period with notable differences $(p<0.05)$ in seventh month to eighth month. The hardness of the noodles was $51.75 \mathrm{~N}$ in the first month and it increased to $57.35 \mathrm{~N}$ at the eighth month. Starch retrogradation is one of the factors limiting the shelf life of noodles according to Owens (2001). The process of starch retrogradation occurred continually along the storage period and thus, the hardness also rose gradually. Besides, the adhesiveness of the noodles showed not much significant difference $(p>0.05)$ with nearly all the 
adhesiveness values of the noodles were in the same group except for the last month of storage. The $\mathrm{pH}$ of the noodles dropped every month and this causes the adhesiveness of the noodles to boost. In addition, there were significant changes $(\mathrm{p}<0.05)$ in the cohesiveness of the noodles. The storage period affects the gluten proteins as significant depolymerisation will occurs during storage and the fractions from the depolymerisation will be more soluble in water and segregated during the cooking of noodles (SilvasGarcia et al., 2014). On the other hand, the springiness of the noodles decreased substantially $(p<0.05)$ from first month to the last month of the accelerated shelf life study except for the fifth and sixth month. In addition, the trend of the noodles's chewiness resembles the springiness with significant difference $(\mathrm{p}<0.05)$ in all months starting from $22.06 \mathrm{~N} \cdot \mathrm{mm}$ to $6.26 \mathrm{~N} \cdot \mathrm{mm}$ except for the fifth and sixth month. The trend of both springiness and chewiness may be attributed to the breaking down of the gluten network and leads to the leaching of the starch to the cooking water as reported by Sozer et al. (2007).

\section{- Microbiological Tests}

The results of the presence of microorganisms over eight months of accelerated shelf life study were summarized in Table 5 illustrates that the the growth of yeast and mold was absent in month 1 as compared to number of bacteria. Moreover, the growth of the bacteria was faster than the yeasts and molds along the storage period by looking at the number of colonies by the end of the storage with the increase by 10 -fold every two month. On the contrary, the growth of the yeasts and molds remained plateau up to fourth month and surged in the fifth month until the last month of the storage period. The slower growth of the yeasts and molds as compared to the bacteria may be explained by the suitable water activity of their growth is around 0.7-0.88. The water acitivity at the beginning of the storage period was very low and thus inhibited the growth of yeast and molds. On the other hand, there were some bacteria which can survive or tolerate in extremely low water activity and low pH like acidophiles and osmophilic bacteria (Wood, 2015).

TABLE IV: MICROBIAL GROWTH IN THE INSTANT NOODLES OF BEST FORMULATION OVER 8 MONTHS

\begin{tabular}{|c|c|c|c|c|}
\hline \multirow{2}{*}{ Month } & \multicolumn{4}{|c|}{ Instant Noodles of Best Formulation } \\
\cline { 2 - 5 } & $\begin{array}{c}\text { Total Plate } \\
\text { Count } \\
(\mathrm{CFU} / \mathrm{g})\end{array}$ & $\begin{array}{c}\text { Total Plate } \\
\text { Count }(\log \\
\text { CFU/g)* }\end{array}$ & $\begin{array}{c}\text { Yeast and } \\
\text { Mold } \\
(\mathrm{CFU} / \mathrm{g})\end{array}$ & $\begin{array}{c}\text { Yeast and } \\
\text { Mold } \\
(\log \text { CFU/g) }\end{array}$ \\
\hline 0 & 0 & 0 & 0 & 0 \\
\hline 1 & $3 \times 10$ & 1.48 & 0 & 0 \\
\hline 2 & $7.5 \times 10$ & 1.87 & $1.1 \times 10$ & 1.04 \\
\hline 3 & $5.4 \times 10^{2}$ & 2.73 & $8.3 \times 10$ & 1.92 \\
\hline 4 & $8.9 \times 10^{2}$ & 2.95 & $9.8 \times 10$ & 2 \\
\hline 5 & $2.6 \times 10^{3}$ & 3.41 & $2.8 \times 10^{2}$ & 2.45 \\
\hline 6 & $8.1 \times 10^{3}$ & 3.91 & $7.4 \times 10^{2}$ & 2.87 \\
\hline 7 & $5.5 \times 10^{4}$ & 4.74 & $4.8 \times 10^{3}$ & 3.68 \\
\hline 8 & $6.9 \times 10^{4}$ & 4.84 & $6.8 \times 10^{3}$ & 3.83 \\
\hline
\end{tabular}

*1 log increase is equivalent to 10 -fold increase in CFU/g.

In overall, the instant noodles are safe to be consumed after stored for eight months. The colony number of bacteria, yeast and molds of the raw instant noodles did not exceed the deterioration threshold limit or the cutoff point of spoiled and unspoiled food, $10^{6} \mathrm{CFU} / \mathrm{g}$ (Li et al., 2011; Ghaffar et al., 2009; Lacroix et al., 2004). The combination of the factors like $\mathrm{pH}$ and water activity has the hurdle effect in generating the shelf stable product.

\section{- Sensory Evaluation: Paired T-test}

The results of the sensory evaluation along the storage period were presented in Figure 8. In terms of taste attribute, the mean rank was not markedly different between months up to sixth month with the decreasing trend from 218.23 to 63.55. Due to considerably high mean rank of the taste attribute, there is high possibility that F3 is free from the problem of lipid hydrolysis. Other than that, the aroma of the noodles experienced the decrement from 223.96 in the first month and obtained the mean rank of 43.90 at the end of the storage period. Similar to taste attribute, the aroma of the noodles did not differ much between months until fifth month. The loss of aroma may be because of the volatile compounds penetrated out of the packaging materials and result in the reduced perception of the quality. For the attribute of colour, the mean rank decreased from 226.00 to 66.00 with not much significant difference $(p>0.05)$ between months up to fifth month. Compared with the mean rank of other attributes, the panellists were still satisfied with the colour of the stored noodles. of storage (Chowdhury et al., 2011). Other than that, the mean rank of texture attribute was 66.50 at the end of the accelerated shelf life study with the decreasing trend along the storage period. The mean rank of texture differed markedly $(\mathrm{p}<0.05)$ starting from seventh month. The results were consistent with the instrumental measurements where TPA and tensile strength tests depicted that the textural properties of the noodles deteriorated over the storage period and showed significant differences $(\mathrm{p}<0.05)$ from sixth month. Besides, for the overall acceptance of the noodles for the paired $t$ test, it gained the highest mean rank which was 81.69 although the downtrend of the mean score can be observed. The score of the overall acceptance is profound as it evaluates the quality of the noodles from various aspects and indicates the palatability of the stored noodles. Thus, it can be concluded that the quality of the instant noodles are preserved not only in terms of safety aspect but also the sensory quality at the end of the storage study.

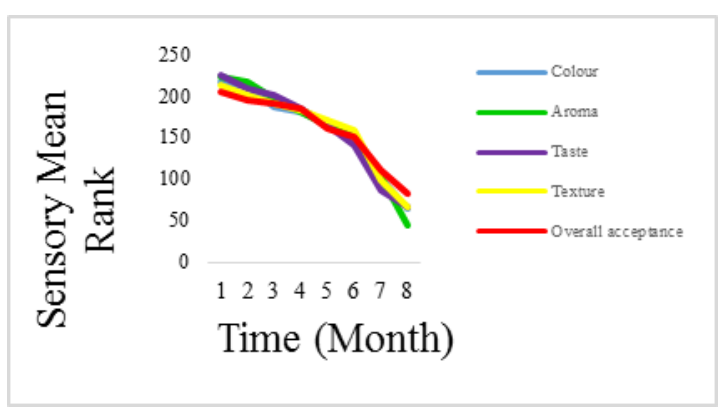

Figure 8: Sensory evaluation of instant noodles of best formulation over eight months 


\section{CONCLUSION}

Chickpea and okara composite flour instant noodles F3 which comprised of $75 \%$ wheat flour, $12.5 \%$ of chickpea and okara flours respectively was chosen the best formulation. The physicochemical properties showed that F3 as the best characters with higher cooking yield, longer optimal cooking time, lower rehydration rate and higher cooking loss than the control. It also contains higher dietary fibre $(10.05 \mathrm{~g} / 100 \mathrm{~g})$ and increases the ash, protein, crude fiber but reduced it crude fat and energy $(9.05 \%)$ and it quality also satisfied throughout the eight months period of storage.

\section{REFERENCES}

[1] AACC. 2000. Approved Methods of the AACC: Method 08-01. 10 $0^{\text {th }}$ ed. St. Paul. Minnesota: AACC International.

[2] Aguilera, Y., Martı'n-Cabrejas, M. A. and Benı'tez V. 2009. Changes in carbohydrate fraction during dehydration process of common legumes. J Food Compos Anal. 22: 678-683.

[3] Alajaji, S. A. and El-Adawy, T. A. 2006. Nutritional composition of chickpea (cicer arietinum 1.) as affected by microwave cooking and other traditional cooking methods. J Food Compos Anal. 19: 806-812

[4] Anderson, J. V. and Morris, C. F. 2001. An improved whole-seed assay for screening wheat germplasm for polyphenol oxidase activity. Crop Science. 41(6): 1697-1705.

[5] AOAC. 2000. Official Methods of Analysis. 17 $7^{\text {th }}$ ed. Washington, DC: AOAC International.

[6] Asenstorfer, R. E., Appelbee, M. J., Kusznir, C. A. and Mares, D. J. 2014. Toward an Understanding of Mechanisms Involved in NonPolyphenol Oxidase (Non-PPO) Darkening in Yellow Alkaline Noodles (YAN). Journal of agricultural and food chemistry. 62(20): 4725-4730.

[7] Asenstorfer, R. E., Appelbee, M. J. and Mares, D. J. 2009. PhysicalChemical Analysis of Non-Polyphenol Oxidase (Non-PPO) Darkening in Yellow Alkaline Noodles. Journal of agricultural and food chemistry. 57(12): 5556-5562.

[8] Aydin, E. and Gocmen, D. 2011. Cooking quality and sensorial properties of noodle supplemented with oat flour. Food Science and Biotechnology. 20(2): 507-511.

[9] Barros, L., Heleno, S. A., Carvalho, A. M. and Ferreira, I. C. F. R. 2010. Lamiaceae often used in Portuguese folk medicine as a source of powerful antioxidants: vitamins and phenolics. LWT-Food Science and Technology. 43: 544-550.

[10] Bourne, M. C. 2002. Principles of objective texture measurement. In Bourne, M. C. (ed). Food texture and viscosity: concept and measurement. 2nd ed. Academic Press: California. pg 107-188.

[11] Chowdhury, K., Khan, S., Karim, R., Obaid, M. and Hasan, G. M. M. A. 2011. Effect of Moisture, Water Activity and Packaging Materials on Quality and Shelf Life of Some Locally Packed Chanachur. Bangladesh Journal of Scientific and Industrial Research. 46(1): 33-40.

[12] Daniel, E., Momoh, S., Friday, E. T. and Okpachi, A. 2014. Evaluation of the biochemical composition and proximate analysis of indomie noodle. International Journal of Medical and Applied Sciences. 3(1): 166-175

[13] Dewi, E. N. 2011. Quality evaluation of dried noodle with seaweeds puree subsitution. Journal of Coastal Development. 14(2): 151-158.

[14] Dueñas, M., Hernández, T., Lamparski, G., Estrella, I. and Muñoz, R. 2012. Bioactive phenolic compounds of soybean (Glycine max cv. Merit): modifications by different microbiological fermentations. Polish Journal of Food and Nutrition Sciences. 62(4): 241-250.

[15] Euromonitor. 2015. Rice, Pasta and Noodles in Malaysia. [Online]. In http://www.portal.euromonitor.com.ezproxy.ums.edu.my/portal/analy sis/tab. [27 March 2016].
[16] Fari, M. J. M., Rajapaksa, D. and Ranaweera, K. K. D. S. 2011. Quality characteristics of noodles made from selected varieties of Sri Lankan rice with different physicochemical characteristics. Journal of the National Science Foundation of Sri Lanka. 39(1).

[17] Foo, W. T., Yew, H. S., Liong, M. T. and Azhar, M. E. 2011 Influence of formulations on textural, mechanical and structural breakdown properties of cooked yellow alkaline noodles. International. Food Research Journal. 18: 1295-1301.

[18] Fuerst, E. P., Anderson, J. V. and Morris, C. F. 2006. Delineating the role of polyphenol oxidase in the darkening of alkaline wheat noodles. Journal of Agricultural and Food Chemistry. 54(6): 2378-2384.

[19] Gazmuri, A. M. and Bouchon, P. 2009. Analysis of wheat gluten and starch matrices during deep-fat frying. Food Chemistry. 115(3): 9991005 .

[20] Ghaffar, S., Abdulamir, A. S., Bakar, F. A., Karim, R. and Saari, N. 2009. Microbial growth, sensory characteristic and $\mathrm{pH}$ as potential spoilage indicators of chinese yellow wet noodles from commercial processing plants. American Journal of Applied Sciences. 6(6): 10591066.

[21] Global Food Forums. 2015. [Online]. In http://www.globalfoodforums.com/about-us/contact-us/. [6 March 2015].

[22] Gulia, N., Dhaka, V. and Khatkar, B. S. 2014. Instant noodles: processing, quality, and nutritional aspects. Critical Reviews in Food Science and Nutrition. 54: 1386-1399.

[23] Guo, G., Jackson, D. S., Graybosch, R. A. and Parkhurst, A. M. 2003. Asian salted noodle quality: Impact of amylose content adjustments using waxy wheat flour. Cereal Chemistry. 80: 437-445.

[24] Hakoda, A., Kasama, H., Sakaida, K., Suzuki, T., Yasui, A. and Kaisha, T. S. 2006. Determination of the moisture content of instant noodles: interlaboratory study. Journal of AOAC International. 89(6): 1585-1590.

[25] Hefnawy, T. M. H., El-Shourbagy, G. A. and Ramadan, M. F. 2012. Impact of adding chickpea (Cicer arietinum L.) flour to wheat flour on the rheological properties of toast bread. International Food Research Journal. 19(2): 521-525.

[26] Huang, Z., Ye, R., Chen, J. and Xu, F. 2013. An improved method for rapid quantitative analysis of the insoluble dietary fiber in common cereals and some sorts of beans. Journal of Cereal Science. 57(3): 270-274.

[27] Hou, G. 2001. Oriental noodles. Advances in Food and Nutrition Research. 43: 142-193.

[28] Hou, G. G. 2010. Asian Noodles: Science, Technology, and Processing. New Jersey: John Wiley \& Sons.

[29] Jankowiak, L., Trifunovic, O., Boom, R. M. and Van der Goot, A. J. 2014. The potential of crude okara for isoflavone production. Journal of Food Engineering. 124: 166-172.

[30] Jayasena, V., Leung, P. P. and Nasar-Abbas, S. M. 2010 Effect of lupin flour substitution on the quality and sensory acceptability of instant noodles. Journal of Food Quality. 33(6): 709727.

[31] Jukanti, A. K., Gauri, P. M., Gowda, C. L. L. and Chibbar, R. N. 2012. Nutritional quality and health benefits of chickpea (Cicer arietinum L.): a review. British Journal of Nutrition. 108: S11-S26

[32] Kaur, G., Sharma, S., Nagi, H. P. S. and Ranote, P. S. 2013. Enrichment of pasta with different plant proteins. Journal of food science and technology. 50(5): 1000-1005.

[33] Karim, R. and Muhammad, T. S. 2015. Yellow Alkaline Noodles: Processing Technology and Quality Improvement. New York: Springer

[34] Khan, A. R., Alam, S., Ali, S., Bibi, S. and Khalil, I. A. 2007. Dietary fiber profile of food legumes. Sarhad Journal of Agriculture. 23(3): 763.

[35] Kumar, S. B. and Prabhasankar, P. 2015. A study on noodle dough rheology and product quality characteristics of fresh and dried noodles as influenced by low glycemic index ingredient. Journal of food science and technology. 52(3): 1404-1413.

[36] Lacroix, M., Ouattara, B., Saucier, L., Giroux, M. and Smoragiewicz, W. 2004. Effect of gamma irradiation in presence of ascorbic acid on microbial composition and TBARS concentration of ground beef coated with an edible active coating. Radiation Physics and Chemistry. 71(1): 73-77.

[37] Lee, J. H., Jeon, J. K., Kim, S. G., Kim, S. H., Chun, T. and Imm, J. Y. 2011. Comparative analyses of total phenols, flavonoids, saponins 
and antioxidant activity in yellow soy beans and mung beans. International Journal of Food Science \& Technology. 46(12): 2513-2519.

[38] Lee, Y. B., Lee, H. J. and Sohn, H. S. 2005. Soy isoflavones and cognitive function. The Journal of nutritional biochemistry. 16(11): 641-649.

[39] Li, M., Ma, M., Zhu, K. X., Guo, X. N. and Zhou, H. M. 2017. Delineating the physico-chemical, structural, and water characteristic changes during the deterioration of fresh noodles: Understanding the deterioration mechanisms of fresh noodles. Food Chemistry. 216: 374-381.

[40] Li, S., Zhu, D., Li, K., Yang, Y., Lei, Z. and Zhang, Z. 2013. Soybean curd residue: composition, utilization, and related limiting factors. ISRN Industrial Engineering. 2013: 1-8.

[41] Li, S., Zhu, D., Li, K., Yang, Y., Lei, Z. and Zhang, Z. 2013. Soybean curd residue: composition, utilization, and related limiting factors. ISRN Industrial Engineering, 2013: 1-8.

[42] Lu, F., Cui, Z. K., Liu, Y. and Li, B. 2013. The Effect of

[43] Okara on the Qualities of Noodles and Steamed Bread. Advance Journal of Food Science and Technology. 5(7): 960-968.

[44] Madhumitha, S. and Prabhasankar, P. 2011. Influence of additives on functional and nutritional quality characteristics of black gram flour incorporated pasta. Journal of Texture Studies. 42(6): 441-450.

[45] Miñarro, B., Albanell, E., Aguilar, N., Guamis, B. and Capellas, M. 2012. Effect of legume flours on baking characteristics of gluten-free bread. Journal of Cereal Science. 56(2): 476-481.

[46] Miyazaki, M., Maeda, T. and Morita, N. 2004. Effect of various dextrin substitutions for wheat flour on dough properties and bread qualities. Food research international. 37(1): 59-65.

[47] Noorfarahzilah, M., Lee, J. S., Sharifudin, M. S., Mohd Fadzelly, A. B. and Hasmadi, M. 2014. Applications of Composite Flour in Development of Food Products. International Food Research Journal. 21(6): 2061-2074.

[48] Omeire, G. C., Nwosu, J. N., Kabuo, N. O., Nwosu, M. O. and Obasi, N. E. 2015. Cooking properties and sensory evaluation of enriched cassava/wheat noodles. International Journal of Innovative Research In Technology \& Science. 3(2): 46-50.

[49] Onyema, C. T., Ekpunobi, U. E., Edowube, A. A., Odinma, S. and Sokwaibe, C. E. 2014. Quality assessment of common instant noodles sold in Nigeria markets. American Journal of Analytical Chemistry. 5(17): 1174

[50] Park, J., Choi, I. and Kim, Y. 2015. Cookies formulated from fresh okara using starch, soy flour and hydroxypropyl methylcellulose have high quality and nutritional value. LWT-Food Science and Technology. 63(1): 660-666.

[51] Park, C. S. and Baik, B. K. 2004. Relationship between protein characteristics and instant noodle making quality of wheat flour. Cereal Chemistry, 81(2): 159-164.

[52] Pérez-López, E., Mateos-Aparicio, I. and Rupérez, P. 2016. Okara treated with high hydrostatic pressure assisted by Ultraflo® L: Effect on solubility of dietary fibre. Innovative Food Science \& Emerging Technologies. 33: 32-37.

[53] Polesi, L. F., Sarmento, S. B. S. and Anjos, C. B. P. 2011. Composition and characterization of pea and chickpea starches. Brazilian Journal of Food Technology. 14: 74-81.

[54] Porwal, V. B., Kumar, S. B., Madhumathi, R. and Prabhasankar, P. 2014. Influence of health based ingredient and its hydrocolloid blends on noodle processing. Food Measure. 8: 283-295.

[55] Purwandari, U., Khoiri, A., Muchlis, M., Noriandita, B., Zeni, N. F., Lisdayana, N. and Fauziyah, E. 2014. Textural, cooking quality, and sensory evaluation of gluten-free noodle made from breadfruit, konjac, or pumpkin flour. International Food Research Journal. 21(4): 1623-1627.
[56] Recundo-Cuenca, A., Villaneuva-Suárez, M. J. and Mateos-Aparicio, I. 2008. Soybean seeds and its by-product okara as sources of dietary fibre. Measurement by AOAC and Englyst methods. Food Chemistry. 108: 1099-1105.

[57] Ritthiruangdej, P., Parnbankled, S., Donchedee, S. and Wongsagonsup, R. 2011. Physical, chemical, textural and sensory properties of dried wheat noodles supplemented with unripe banana flour. Kasetsart Journal-Natural Science. 45(3): 500-509.

[58] Robbins, R. J. 2003. Phenolic acids in foods: an overview of analytical methodology. Journal of agricultural and food chemistry. 51(10): 2866-2887

[59] Shin, J. M., Hwang, Y. O., Tu, O. J., Jo, H. B., Kim, J. H., Chae, Y. Z., Rhu, K. H. and Park, S. K. 2013. Comparison of different methods to quantify fat classes in bakery products. Food chemistry. 136(2): 703-709.

[60] Silvas-García, M. I., Ramírez-Wong, B., Torres-Chávez, P. I., Carvajal-Millan, E., Barrón-Hoyos, J. M., Bello-Pérez, L. A. and Quintero-Ramos, A. 2014. Effect of freezing rate and storage time on gluten protein solubility, and dough and bread properties. Journal of Food Process Engineering. 37(3): 237-247.

[61] Sozer, N., Dalgıç, A. C. and Kaya, A. 2007. Thermal, textural and cooking properties of spaghetti enriched with resistant starch. Journal of Food Engineering, 81(2), 476-484.

[62] Sramková, Z., Gregová, E. and Šturdík, E. 2009. Chemical composition and nutritional quality of wheat grain. Acta Chimica Slovaca. 2(1): 115-138.

[63] Sreerama, Y. N., Sashikala, V. B., Pratape, V. M. and Singh, V. 2012. Nutrients and antinutrients in cowpea and horse gram flours in comparison to chickpea flour: Evaluation of their flour functionality. Food Chemistry. 131: 462-468.

[64] Syamaladevi, R. M., Tadapaneni, R. K., Xu, J., Villa-Rojas, R., Tang, J., Carter, B., Sablani, S. and Marks, B. 2016. Water activity change at elevated temperatures and thermal resistance of Salmonella in all purpose wheat flour and peanut butter. Food Research International. 81: 163-170.

[65] Thomas, R., Yeoh, T. K., Wan-Nadiah, W. A. and Bhat, R. 2014. Quality evaluation of flat rice noodles (kway teow) prepared from bario and basmati rice. Sains Malaysiana. 43(3): 339-347.

[66] Ugarcic-Hardi, Z., Hackenberger, D., Subaric, D. and Hardi, J. 2003. Effect of soy, maize and extruded maize flour addition on physical and sensory characteristics of pasta. Italian journal of food science. 15(2): 277-286.

[67] Wang, N. and Daun, J. K. 2004. The chemical composition and nutritive value of Canadian pulses. In Canadian Grain Commission Report. 19-29.

[68] Wickramarathna, G. L. and Arampath, P. C. 2003. Utilization of okara in bread making. Journal of Bioscience. 31: 29-33.

[69] Wood, J. M. 2015. Bacterial responses to osmotic challenges. The Journal of general physiology. 145(5): 381-388.

[70] World Instant Noodle Association (WINA). 2015. Global Demand for Instant Noodles. [Online]. In https://instantnoodles.org/pdf/2015en.pdf. [6 March 2016].

[71] Zawawi, N., Gangadharan, P., Ahma Zaini, R., Samsudin, M. G., Karim, R. and Ismail, M. 2014. Nutritional values and cooking quality of defatted kenaf seeds yellow (DKSY) noodles. International Food Research Journal. 21(2): 603-608. 